\title{
Nutritional status of children (6-59 months) from food secure and food insecure households in rural communities of Saesie Tsaeda-Emba District, Tigray, North Ethiopia: Comparative study
}

\author{
Amaha Kahsay, ${ }^{1, *}$, Afework Mulugeta ${ }^{2}$, Omer Seid $^{2}$ \\ ${ }^{1}$ Department of Public Health, College of Medicine and Health Sciences, Wollo University, Dessie, Ethiopia \\ ${ }^{2}$ Department of Public Health, College of Medicine and Health Sciences, Mekelle University, Mekelle, Ethiopia \\ Email address: \\ amahakahsay@gmail.com (A. Kahsay), afework.mulugeta@gmail.com (A. Mulugeta), seoumer@yahoo.com (O. Seid)
}

\section{To cite this article:}

Amaha Kahsay, Afework Mulugeta, Omer Seid. Nutritional Status of Children (6-59 Months) from Food Secure and Food Insecure Households in Rural Communities of Saesie Tsaeda-Emba District, Tigray, North Ethiopia: Comparative Study. Clinical Medicine Research. Vol. 4, No. 1, 2015, pp. 51-65. doi: 10.11648/j.ijnfs.20150401.18

\begin{abstract}
The aim of this study was to Assess and compare nutritional status and associated factors of 6 to 59 months old children from food secure and food insecure households in rural Kebeles of Saesie Tsaeda Emba district, Tigray, North Ethiopia. As a result, a comparative, cross sectional study was conducted on 841 children (421 from food secure and 420 from food insecure households) from February to March, 2014. Multistage sampling method was used to select Children from each kebele. Anthropometric measurements were entered and calculated using ENA for SMART 2007software then transferred to SPSS version 20 to be processed and analyzed. Bivariate and multivariable logistic regressions were used to identify associated factors of under nutrition at significance level p-value $<0.05$. About $(46.1 \%, 52.1 \%),(18.1 \%, 20.5 \%)$, and $7.1 \%, 12.6 \%)$ of the children from the food secure and food insecure kebelles were stunted, underweight and wasted respectively. Occupation of father, head of family, and duration of continued breast feeding were the factors associated with stunting in food secure households. Whereas age of the child, head of family, and duration of continued breast feeding were determinant factors for stunting in children from the food insecure households. Similarly, educational status of father, sex of the child, and current breast feeding status of the child were the factors associated with underweight for children from food secure households and age of mother, occupational status of father, sex of child, $1^{\text {st }}$ complementary food given to the child, and main source of water to the household were the main predictors of underweight in the food insecure households. The factors associated with child wasting in the food secure households were age of the father and number of cattle owned by the household and age of child and main source of water to the household were the factors associated with child wasting from the food insecure households. Finally, under nutrition among under-five years of age children was very high in the population. Therefore, addressing food security and then nutrition security using the productive safety net program in harmony with participation of all responsible bodies is crucial; as children of the food secure households were at better nutritional outcomes when compared to those of food insecure households.
\end{abstract}

Keywords: Nutritional Status, Under-Five Children, Food Security, Food Insecurity

\section{Introduction}

Nutrition is the cornerstone of socioeconomic development of a country. It is an essential component of millennium development goals (MDGs) and Primary Health Care (1). Nutritional status of under-five children in particular is often considered as one of the most important indicator of a household's living standard and also an important determinant of child survival (2). Malnutrition is responsible for nearly half $(45 \%)$ of all deaths in children under five and responsible for around 3.1 million deaths in children under five annually (3).

Globally, in 2011, nearly one in four children under-five years of age (165 million or 26 per cent) were stunted, 16 percent (estimated 101 million children under five years of age) underweight, 52 million children under five were moderately or severely wasted, and an estimated 43 million 
children under-five were overweight (4).

Regionally, Sub-Saharan Africa and South Asia are home to three fourths of the world's stunted children. In subSaharan Africa, $40 \%$ of children under-5 years of age are stunted; in South Asia, 39\% are stunted. Underweight prevalence is highest in South Asia, which has a rate of 33 per cent, followed by sub-Saharan Africa, at 21 per cent. The highest wasting prevalence is in South Asia, where approximately one in six children $(16 \%)$ is moderately or severely wasted. In sub-Saharan Africa, nearly 1 in 10 children under the age of 5 (9 per cent) were wasted in 2011.

Nationally, according to EDHS 2011, the prevalence of stunting, wasting, under weight and over weight in Ethiopia was $44.4 \%, 9.7 \%, 28.7 \%$ and $2 \%$ and in Tigray, it was found to be $51.4 \%, 10.3 \%, 35.1 \%$, and $0.2 \%$, respectively (5).

The underlying causes of malnutrition are food security, care and healthy environment. Food security at the household and individual level is a necessary but not sufficient condition for adequate nutrition (6). In Ethiopia, as in many other African countries, there is a pressing need to improve household food security (7). Recognizing this, in 2004 the Government of Ethiopia initiated a Productive Safety Net Program with the objectives of reducing household vulnerability, improving household and community resilience to shocks and breaking the cycle of dependence on food aid (8). The purpose of the program is to improve the efficiency and productivity of transfers to food insecure households, thereby reducing household vulnerability, improving resilience and promoting sustainable community development (8).

Ethiopia's approach to nutrition has been relief oriented and focused on food insecurity. Ethiopia is the largest recipient of food aid in the world (9). Ethiopia is striving forward to ensure food security and become food self sufficient. Food security is one of the pillars of improved nutrition status but it doesn't necessarily mean that food secure households are nutritionally secured. Malnutrition is common in many food secure households (10); and still, there was no study done that compares nutritional status of children who live in food secure and food insecure households based on the PSNP criteria. Therefore; the objective of this study was to assess and compare the nutritional status of under- five children from food secure and food insecure households. As a result, children of the food secure households were found at better nutritional outcomes when compared to those children of food insecure households.

\section{Methods and Materials}

\subsection{Study Setting}

Community based comparative cross-sectional study was conducted in Saesie Tsaeda Emba District, from Eastern Tigray, North Ethiopia, between February and March 2014. The District is $83 \mathrm{~km}$ away from Mekelle, the capital city of Tigray. According to the District's survey in 2006 E.C, it has a total population of 169,008 out of which 83,152 are males and 85,856 are females. And the total under-five years of age population are 24,675 out of which 12,535 are females and 12,140 are males. It has also 21,886 six month to five years of age population in which 11,118 are females and 10,768 are males. The total households of the District are 38,441 of which 19,500 households are food insecure which are beneficiary of Productive Safety Net Program and 18,941 are food secure households which are non-beneficiary and/or graduated from Productive Safety Net Program. There are 11,102 six month to five years of age children in the total food insecure households and 10,784 in the total food secure households. This District is one of the beneficiaries of Productive Safety Net Program.

The study participants were All 6 months to 5 years of age children-mothers pair who were residents of the District during the data collection period. All 6 months to 5 years of age children who were with severe illness and deformities which cause difficulty for measurement were excluded from the study.

\subsection{Food Security Status of the Households and the Productive Safety Net Program}

For the purposes of the Safety Net, a district is considered chronically food insecure if it (a) is in one of 8 regions (Tigray, Amhara, Oromiya, SNNP, Afar, Somali, rural Harare and Dire Dawa), and (b) has been a recipient of food aid for a significant period, generally for at least each of the last 3 years. As a result, the study district is found in Tigray and it was a recipient of food aid for many years till now and classified as chronic food insecure district. According to the district's survey in 2014, the total households of the district were 38,441 of which 18,941 were food secure HHs; because, as to the PSNP these households were beneficiaries of that program and they were getting assistances in the form of cash and food aids for years; and now they become graduated from that program and stayed more than one year being out of the PSNP and they were said to self sufficient. Nowadays, they are rearing livestock, working on irrigations and practicing petty trade activities by themselves. So, these households were classified as food secures households as to the PSNP. Whereas, the rest $19,500 \mathrm{HHs}$ are getting assistance in the form of cash and food aid in which the cash is given to those households with ablebodied members so that they repay it by working in any developmental activities like water and soil conservation that is twenty five days per a month whereas, the food aid is given to those households with no able-bodied members; and all these households were classified as food insecure households based on the PSNP. So, it was this predetermined criteria that we used for the classification of the households as food secure and food insecure for our study; as our intention was to see if there was significant nutritional outcome difference to those already said to be food secure and food insecure households based on the PSNP.

\subsection{Sample Size and Sampling Procedure}

\subsubsection{Sample Size Determination}

According to the study from the two districts of North Showa Zone (11), the overall prevalence of stunting, 
underweight and wasting were $54.2 \%, 40.2 \%$ and $10.6 \%$, respectively. And this prevalence (P1) was used here for the food insecure households as it was directly found from a study of nutritional status of children in food insecure households. And for those food secure households, prevalence with standard $10 \%$ difference was considered and thus became $44.2 \%, 30.2 \% \quad 0.6 \%$ (P2) for the above indicators respectively.

Sample size was determined by two population estimation formula. Thus, the calculated total sample sizes multiplied by design effect of 2 were; 782, 712, and 164 for stunting, underweight, and wasting respectively. Hence, the largest of the three sample sizes was considered for this study. Including $10 \%$ for non response rate, the total sample size was calculated to be $782+782(10 \%)$ equals to 860 . So, 430 HHs were selected from each of the food insecure and secure communities.

\subsubsection{Sampling Procedure}

A multi stage sampling method was used; in which, firstly, Tsaeda Emba District was selected purposively as study site as it is a beneficiary of PSNP; because, the summer rainfall is generally late, poor and erratic which this resulted in less yield production. Thus, from this District, seven rural kebeles were selected randomly with lottery method for the current study. After this, all the households in these seven kebeles were stratified into food secure and food insecure households based on the PSNP. Following this, list of 6 months to 5 years of age children in both the food secure and food insecure households were obtained from the District's 2006 E.C survey and the District's food security task force.

Next, the total sample size (860) was divided equally into two; 430 for the food secure households and 430 for the food insecure households. Thus, the two divided sample sizes were distributed to each of the seven kebelles food secure and food insecure households with 6 months to 5 year of age children, using proportionate allocation. After allocating sample size to each kebelle of the food secure and food insecure households, the required sample size of 6 months to 5 years of children were selected using systematic sampling technique. A single child was selected by lottery method from the households in whom $\geq$ two 6 months to 5 years children were found.

\subsection{Data Collection Procedures and Quality Control}

Quantitative data were collected using structured interviewer administered questionnaire \& interview and anthropometric measurements were used as a source of data. The questionnaire was adapted from different relevant studies and was first developed in English and then were translated \& printed in to Tigrigna and back translated to English by different persons to check for their consistency. In addition to the socio-economic and demographic factors, data on the child feeding, maternal and child care, hygiene and sanitation practices, and dietary diversity on household and individual levels were collected.

For the household dietary diversity score a total of 12 food groups and 9 food groups for individual dietary diversity score of children 6 months to 5 years of age were adopted from the FAO. Thus, the study subjects were asked to recall all foods consumed by any household member in the past 24 hours. Finally, households were classified into two categories as low household dietary diversity score if the score was less than mean and high household dietary diversity score if $\geq$ mean of the total score. Whereas, for children 6 months to 5 years were scored as high individual dietary diversity score if the score out of the 9 was $\geq 4$ and as low individual dietary diversity score if $<4$ (12).

All the data were collected by health care workers (diploma nurses) who were given training on the style of the questionnaire and the way how to collect data; and the overall activity was coordinated by the investigator. Data quality was addressed by training data collectors \& supervisors (degree in public health) and providing day to day supervision during the whole period of data collection. Pretest was conducted in other nearby kebele and there were no items that need adjustments. The supervisors were responsible to care of smooth process of data collection process. At the end of each day, the questionnaires were checked for completeness. Then, data was handled and stored carefully and appropriately.

Anthropometric measurements: Age, sex, weight and height were recorded.

Age: Was collected from the mother and counter checked using any available vaccination cards, baptismal certificates or other forms of informal recording. When these recordings were not available, a calendar of locally important events was used. The 15th day of the month was used when the date of birth was unknown and if the month of birth was unknown, the midpoint of the year of birth was used.

Sex: was recorded as female and male.

Weight: Weight of the lightly clothed infants and children were measured to the nearest $100 \mathrm{~g}$ by UNICEF weighting Scale. The weighting scale was calibrated by known $2.5 \mathrm{~kg}$ material after every measurement.

Height: Height of infants aged 6-23 months were measured in a recumbent position to the nearest $0.1 \mathrm{~cm}$ using a board with an upright wooden base and a movable headpiece being the child barefooted and free of head wearing; height of children 24 months and older were measured in a standing-up position to the nearest $0.1 \mathrm{~cm}$ using a measuring board, the child being barefooted and free of any head wearing.

Finally, 2006/WHO growth standards Z-score system of ENA SMART soft ware was used to calculate height-for-age (HAZ), weight-for-age (WAZ) and weight-for-height (WHZ) Z-scores. Children with HAZ, WAZ and WHZ below -2 were characterized as stunted, underweight and wasted, respectively. These variables were considered as the dependent variables during statistical analysis.

\subsection{Data Processing and Analysis}

The data were entered, sorted; cleaned and analyzed using SPSS version 20 and anthropometric measurements were calculated using ENA SMART software and were transferred to SPSS version 20 for analysis. 
Binary logistic regression was used to see the independent effect of predictors on outcome variables. Candidate variables from bivariate analysis were selected and transferred to multi variable binary logistic regression by using pre set p-value of $<$ 0.25 to include important variables (13).

Enter method standard regression model building technique was used to build final model. Before building final model, multi co linearity effect was assessed and the mean VIF $>5$ was used as cut off point (13). Furthermore, confounding was managed using the multivariable analysis. The final model was then tested for its goodness of fit by Hosmer and Lemeshow p-value and $>0.05$ was best fit and all the models were fit for the respective outcome variables. Significance was declared when $\mathrm{p}$-value was $<0.05$.

\subsection{Ethical Statements}

The study was ethically cleared by the Institutional Review Board of the College of Health Sciences of Mekelle University. The rationale and research protocol of the study was explained to the participants before the start of any data collection and written consent was obtained from them. Finally, all information given by the study participants was kept strictly confidential.

\section{Result}

\subsection{Socio-Economic and Demographic Characteristics}

Table 1. Socio-economic and demographic characteristics of the respondents from food secure and food insecure households of rural communities of Saesie Tsaeda Emba District, Eastern Tigray zone, $2014(n 1=421, n 2=420)$.

\begin{tabular}{|c|c|c|c|c|c|}
\hline \multirow{3}{*}{ Variables } & & \multicolumn{4}{|c|}{ PSNP classification of $\mathrm{HHs}$} \\
\hline & & \multirow{2}{*}{$\begin{array}{l}\text { FS HHs }(n=421) \\
\text { Frequency No }(\%)\end{array}$} & \multicolumn{3}{|l|}{ FI HHs $(n=420)$} \\
\hline & & & Frequency No (\%) & COR(95\% CI) & AOR(95\%CI) \\
\hline \multirow{2}{*}{ Age of child } & 6-24 months & $249(59.1)$ & $233(55.5)$ & $.861(.655,1.131)$ & \\
\hline & $\geq 25$ months & $172(40.9)$ & $187(44.5)$ & 1 & 1 \\
\hline \multirow{3}{*}{$\begin{array}{l}\text { Marital status of } \\
\text { mother* }\end{array}$} & Married & $362(86)$ & $356(84.8)$ & & \\
\hline & Divorced & $54(12.8)$ & $55(13.1)$ & & \\
\hline & Others (single, widowed) & $5(1.2)$ & $9(2.1)$ & & \\
\hline \multirow{3}{*}{$\begin{array}{l}\text { Educational level of } \\
\text { mother }\end{array}$} & Unable to read and Write & $248(58.9)$ & $268(63.8)$ & $1.378(.880,2.158)$ & $1.285(.648,2.550)$ \\
\hline & able to read and write & $122(29)$ & $112(26.7)$ & $1.170(.719,1.905)$ & $.925(.475,1.803)$ \\
\hline & Elementary School \& above & $51(12.1)$ & $40(9.5)$ & 1 & 1 \\
\hline \multirow{3}{*}{$\begin{array}{l}\text { Educational level of } \\
\text { father }\end{array}$} & Unable to read and Write & $85(23.5)$ & $60(16.8)$ & $.876(.538,1.426)$ & $.638(.336,1.211)$ \\
\hline & Able to read and write & $210(58)$ & $243(68.1)$ & $1.436(.959,2.149)$ & $1.314(.743,2.323)$ \\
\hline & Elementary School \& above & $67(18.5)$ & $53(14.9)$ & 1 & 1 \\
\hline \multirow{2}{*}{$\begin{array}{l}\text { Occupational status } \\
\text { mother }\end{array}$} & House wife & $407(96.7)$ & $406(96.7)$ & 1 & 1 \\
\hline & Others(daily laborers, herders) & $14(3.3)$ & $14(3.3)$ & $1.002(.472,2.130)$ & $1.107(.423,2.898)$ \\
\hline \multirow{3}{*}{$\begin{array}{l}\text { Occupational status } \\
\text { father }\end{array}$} & Daily laborer & $49(13.5)$ & $34(9.5)$ & 1 & 1 \\
\hline & Farmer & $266(73.5)$ & $272(76.4)$ & $1.474(.922,2.355)$ & $1.484(.855,2.578)$ \\
\hline & Others(herders, merchants) & $47(13)$ & $50(14.1)$ & $1.531(.850,2.759)$ & $1.414(.767,2.606)$ \\
\hline \multirow{2}{*}{ Head of family } & Father & $77(18.3)$ & $86(20.5)$ & 1 & 1 \\
\hline & Mother & $344(81.7)$ & $334(79.5)$ & $.869(.617,1.224)$ & $.764(.425,1.372)$ \\
\hline \multirow{2}{*}{$\begin{array}{l}\text { No of individuals in } \\
\mathrm{HH}\end{array}$} & $<5$ & $163(38.7)$ & $139(33.1)$ & 1 & 1 \\
\hline & $\geq 5$ & $258(61.3)$ & $281(66.9)$ & $1.277(.963,1.694)$ & $1.450(.952,2.211)$ \\
\hline \multirow{3}{*}{$\begin{array}{l}\text { No of cattle owned } \\
\text { by HH }\end{array}$} & No cattle & $129(30.6)$ & $129(30.7)$ & 1 & 1 \\
\hline & Only one & $76(18.1)$ & $81(19.3)$ & $1.066(.717,1.585)$ & $.763(.437,1.330)$ \\
\hline & $\geq 2$ & $216(51.3)$ & $210(50)$ & $.972(.714,1.325)$ & $.683(.401,1.163)$ \\
\hline \multirow{3}{*}{$\begin{array}{l}\text { No of sheep/goat in } \\
\text { the HH }\end{array}$} & No sheep/goat & $122(29)$ & $103(24.5)$ & $.802(.589,1.092)$ & $1.147(.493,2.672)$ \\
\hline & Only one & $16(3.8)$ & $19(4.5)$ & $1.128(.569,2.236)$ & $1.138(.657,1.971)$ \\
\hline & $\geq 2$ & $283(67.2)$ & $298(71)$ & 1 & 1 \\
\hline \multirow{2}{*}{$\begin{array}{l}\text { Sex of the study } \\
\text { child }\end{array}$} & Female & $216(51.3)$ & $221(52.6)$ & $1.054(.804,1.381)$ & $1.139(.842,1.541)$ \\
\hline & Male & $205(48.7)$ & $199(47.4)$ & 1 & 1 \\
\hline
\end{tabular}

PSNP - Productive Safety Net Program

FSHHs - Food Secure Households

FIHHs - Food Insecure Households

* The variables cannot be computed in statistical analysis as some of their categories are $<5 \%$

Eight hundred forty one (421 from food secure and 420 from food insecure households) children who were 6 months to 5 years of age participate in the study making response rate of $97.9 \%$ for food secure households and $97.6 \%$ for food insecure households. All care takers for the children in both food secure and food insecure households were mothers 
which was $100 \%$ and $99.5 \%$, respectively. The mean age of mothers was 31.83 years with a standard deviation of \pm 5.51 for food secure and 32.56 years with a standard deviation of \pm 5.58 for food insecure households. Age distribution of mothers was similar in both groups with a mean age difference of less than one year between the two groups and this difference was not statistically significant $(\mathrm{p}=0.806$, $95 \% \mathrm{CI}: 1.482,0.021)$. And for fathers the mean age $( \pm \mathrm{sd})$ was $38.36( \pm 6.92)$ and $40.07( \pm 7.53)$ years from the food secure and food insecure households, respectively. All parents for the children in both food secure and food insecure households were Orthodox Christian followers which was $100 \%$ and $99.3 \%$, respectively (table 1 ).

\subsection{Child Feeding Practices}

All the mothers (100\%) from both the food secure and food insecure had ever breast fed their children. Similarly, $421(100 \%)$ and $419(99.8 \%)$ of the mothers from the food secure and food insecure households initiated BF within the first hour after delivery, respectively.

In addition, 419(99.5\%) and 417(99.3\%) of the mothers from food secure and food insecure households gave colostrums to their newborns immediately after birth, respectively. In contrast, Milk was the predominant prelacteal feed in the study communities. Eleven (73\%) and $20(69 \%)$ of the mothers from food secure and food insecure households gave milk as the pre-lacteal feed to their newborns after delivery, respectively. Complementary feeding was started at 6 month of age to all the children $(100 \%)$ from both the food secure and food insecure households respectively (table 2 ).

Table 2. Child feeding practices of the respondents from food secure and food insecure households of rural communities of Saesie Tsaeda Emba District, Eastern Tigray zone, $2014(n 1=421, n 2=420)$.

\begin{tabular}{|c|c|c|c|c|c|}
\hline \multirow{3}{*}{ Variable name } & & \multicolumn{4}{|c|}{ PSNP classification of $\mathrm{HHs}$} \\
\hline & & \multirow{2}{*}{$\begin{array}{l}\text { FS HHs }(n=421) \\
\text { Frequency No (\%) }\end{array}$} & \multicolumn{3}{|l|}{ FI HHs $(n=420)$} \\
\hline & & & Frequency No (\%) & $\operatorname{COR}(95 \% \mathrm{CI})$ & $\operatorname{AOR}(95 \% C I)$ \\
\hline \multirow{2}{*}{$\begin{array}{l}\text { How frequent BF the } \\
\text { child* }\end{array}$} & $\geq 8$ times & $412(97.9)$ & $409(97.4)$ & & \\
\hline & Others $(<8 \mathrm{x}$, only when cries $)$ & $9(2.1)$ & $11(2.6)$ & & \\
\hline \multirow{3}{*}{$\begin{array}{l}\text { How many months BF } \\
\text { the child }\end{array}$} & $1-2$ years & $268(63.7)$ & $248(59)$ & $.925(.528,1.621)$ & $.907(.509,1.618)$ \\
\hline & $>=2$ years & $126(29.9)$ & $145(34.5)$ & $1.151(.641,2.064)$ & $1.051(.575,1.921)$ \\
\hline & $<1$ year & $27(6.4)$ & $27(6.4)$ & 1 & 1 \\
\hline \multirow{2}{*}{$\begin{array}{l}\text { Current BF status of the } \\
\text { child }\end{array}$} & Partial Breastfeeding & $265(62.9)$ & $260(61.9)$ & 1 & 1 \\
\hline & Not Breastfeeding & $156(37.1)$ & $160(38.1)$ & $.957(.724,1.265)$ & $.968(.722,1.297)$ \\
\hline \multirow{2}{*}{$\begin{array}{l}\text { Given anything else } \\
\text { immediately after birth }\end{array}$} & Yes & $15(3.6)$ & $29(6.9)$ & $2.008(1.060,3.802)$ & $.588(.086,4.037)$ \\
\hline & No & $406(96.4)$ & $391(93.1)$ & 1 & 1 \\
\hline \multirow{2}{*}{ Age CF started } & 6-12 months & $411(97.6)$ & $415(98.8)$ & 1 & 1 \\
\hline & Others $(<6$ months, $1-2 \mathrm{yrs}, \geq 2 \mathrm{yrs})$ & $10(2.4)$ & $5(1.2)$ & $.495(.168,1.461)$ & $.391(.121,1.266)$ \\
\hline \multirow{3}{*}{$\begin{array}{l}\text { The 1st complementary } \\
\text { food started }\end{array}$} & Milk & $105(24.9)$ & $94(22.4)$ & $.874(.633,1.206)$ & $.844(.579,1.230)$ \\
\hline & Adult Food & $29(6.9)$ & $32(7.6)$ & $1.077(.635,1.827)$ & $1.966(1.004,3.850)$ \\
\hline & Porridge & $287(68.2)$ & $294(70)$ & 1 & 1 \\
\hline \multirow{3}{*}{$\begin{array}{l}\text { How frequent feed the } \\
\text { child }\end{array}$} & $<3 \mathrm{x}$ & $51(12.1)$ & 49 (11.7) & $.895(.465,1.721)$ & $1.073(.528,2.181)$ \\
\hline & $>=3 x$ & $343(81.5)$ & $342(81.4)$ & $.928(.538,1.601)$ & $.758(.402,1.429)$ \\
\hline & Only when cries & $27(6.4)$ & $29(6.9)$ & 1 & 1 \\
\hline \multirow{3}{*}{$\begin{array}{l}\text { What is used to feed the } \\
\text { child }\end{array}$} & Hand & $84(20)$ & $60(14.3)$ & 1 & 1 \\
\hline & Cup and Spoon & $332(78.9)$ & $353(84)$ & $1.489(1.035,2.141)$ & $2.110(1.273,3.496)$ \\
\hline & Bottle & $5(1.2)$ & $7(1.7)$ & $1.960(.594,6.472)$ & $2.641(.728,9.578)$ \\
\hline
\end{tabular}

PSNP - Productive Safety Net Program

FSHHs - Food Secure Households, FIHHs - Food Insecure Households

* The variables cannot be computed in statistical analysis as some of their categories are $<5 \%$

\subsection{Maternal and Child Care Characteristics}

Four hundred eighteen $(99.3 \%)$ and $415(98.8 \%)$ mothers from food secure and food insecure households had ANC follow up during their previous pregnancy for the study child, respectively. Two hundred eight (68.4\%) and $275(65.5 \%)$ of the mothers from food secure and food insecure households gave birth at health facilities for their previous pregnancy for 
the study child, respectively. Similarly, 419(99.5\%) and $418(99.5 \%)$ of the children from food secure and food insecure households had ever received vaccination, respectively (table 3 ).

Table 3. Maternal and child care characteristics of the respondents from food secure and food insecure households of rural communities of Saesie Tsaeda Emba District, Eastern Tigray zone, $2014(n 1=421, n 2=420)$.

\begin{tabular}{|c|c|c|c|c|c|}
\hline \multirow{3}{*}{ Variable name } & & \multicolumn{4}{|l|}{ PSNP classification of $\mathrm{HHs}$} \\
\hline & & \multirow{2}{*}{$\begin{array}{l}\text { Food Secure HHs }(n=421) \\
\text { Frequency No }(\%)\end{array}$} & \multicolumn{3}{|l|}{$\begin{array}{l}\text { Food Insecure HHs } \\
(n=420)\end{array}$} \\
\hline & & & Frequency No (\%) & $\operatorname{COR}(95 \% \mathrm{CI})$ & $\operatorname{AOR}(95 \% C I)$ \\
\hline \multirow{2}{*}{$\begin{array}{l}\text { Had mother ANC follow } \\
\text { up for this child }\end{array}$} & Yes & $418(99.3)$ & $415(98.8)$ & $.596(.141,2.509)$ & $2.521(.131,48.571)$ \\
\hline & No & $3(0.7)$ & $5(1.2)$ & 1 & 1 \\
\hline \multirow{3}{*}{ Place of birth for this child } & Home & $133(31.6)$ & $145(34.5)$ & 1 & 1 \\
\hline & Health Facility & $288(68.4)$ & $275(65.5)$ & $.876(.657,1.168)$ & $.276(.071,1.070)$ \\
\hline & TBA & $40(9.5)$ & $31(7.4)$ & 1 & 1 \\
\hline \multirow[t]{2}{*}{ Who attended the delivery } & Health Personnel & $299(71)$ & $278(66.2)$ & $1.200(.730,1.971)$ & $6.881(1.337,35.425)$ \\
\hline & Others & $82(19.5)$ & $111(26.4)$ & $1.747(1.009,3.024)$ & $3.847(1.000,14.796)$ \\
\hline \multirow{2}{*}{$\begin{array}{l}\text { Child weighed in the last } 3 \\
\text { months }\end{array}$} & Yes & $351(83.4)$ & $334(79.5)$ & $1.291(.910,1.831)$ & $.319(.118, .862)$ \\
\hline & No & $70(16.6)$ & $86(20.5)$ & 1 & 1 \\
\hline \multirow{4}{*}{$\begin{array}{l}\text { Child ever receive } \\
\text { vaccination* } \\
\text { Does the child have } \\
\text { vaccination card* }\end{array}$} & Yes & $419(99.5)$ & $418(99.5)$ & & \\
\hline & No & $2(0.5)$ & $2(0.5)$ & & \\
\hline & Yes & $410(94.7)$ & $418(99.5)$ & & \\
\hline & No & $11(2.6)$ & $2(0.5)$ & & \\
\hline \multirow{4}{*}{$\begin{array}{l}\text { Did the child sick in last } 2 \\
\text { weeks }\end{array}$} & Yes & $70(16.6)$ & $89(21.2)$ & 1 & 1 \\
\hline & No & $351(83.4)$ & $331(78.8)$ & $.742(.524,1.050)$ & $.573(.354,1.125)$ \\
\hline & Fever & $19(27.1) \#$ & $28(31.5) \#$ & 1 & 1 \\
\hline & Cough & 15 (21.4)\# & $20(22.5) \#$ & $.905(.372,2.198)$ & $1.055(.410,2.710)$ \\
\hline \multirow[t]{2}{*}{ Type of the illness } & Diarrhea & $30(42.9) \#$ & $37(41.6) \#$ & $.837(.393,1.782)$ & $.882(.383,2.030)$ \\
\hline & Others & $6(8.6) \#$ & $4(4.5) \#$ & $.452(.112,1.821)$ & $.877(.200,3.842)$ \\
\hline
\end{tabular}

\# The percentages show from those who said 'yes' for a child if sick in the previous 2 weeks; not from total subjects.

*The variables cannot be computed in statistical analysis as some of their categories are $<5 \%$

\subsection{Water, Hygiene and Sanitation Characteristics}

The sources of water for majority of the food secure (73.4\%) and food insecure $(71.7 \%)$ households was hand pump. By the same token, pit latrine was the commonest type of latrine for both the food secure $(82.2 \%)$ and food insecure $(83.8 \%)$ households. Almost all of the mothers from the food secure $(99.3 \%)$ and food insecure $(100 \%)$ practiced hand washing before and after feeding the child (table 4 ).

Table 4. Water source, sanitation and hygienic characteristics of the respondents from food secure and food insecure households of rural communities of Saesie Tsaeda Emba District, Eastern Tigray zone, $(n 1=421, n 2=420)$.

\begin{tabular}{|c|c|c|c|c|c|}
\hline \multirow{3}{*}{ Variable name } & & \multicolumn{4}{|c|}{ PSNP classification of $\mathrm{HHs}$} \\
\hline & & \multirow{2}{*}{$\begin{array}{l}\text { Food Secure HHs }(n= \\
421) \\
\text { Frequency No }(\%)\end{array}$} & \multicolumn{3}{|l|}{$\begin{array}{l}\text { Food Insecure HHs } \\
(n=420)\end{array}$} \\
\hline & & & Frequency No (\%) & COR(95\% CI) & $\operatorname{AOR}(95 \% C I)$ \\
\hline \multirow{4}{*}{$\begin{array}{l}\text { Main source of water in the } \\
\text { household }\end{array}$} & Protected well/Spring & $32(7.6)$ & $27(6.4)$ & $.866(.507,1.481)$ & $.876(.512,1.499)$ \\
\hline & Unprotected well/Spring & $57(13.5)$ & $64(15.2)$ & $1.153(.780,1.704)$ & $1.190(.797,1.776)$ \\
\hline & River water & $23(5.5)$ & $28(6.7)$ & $1.250(.704,2.219)$ & $1.230(.692,2.187)$ \\
\hline & Pipe(hand pump) & $309(73.4)$ & $301(71.7)$ & 1 & 1 \\
\hline \multirow{2}{*}{$\begin{array}{l}\text { Does the household have } \\
\text { latrine }\end{array}$} & Yes & $346(82.2)$ & $352(83.8)$ & $1.122(.783,1.609)$ & $.874(.603,1.268) 3$ \\
\hline & No & $75(17.8)$ & $68(16.2)$ & 1 & 1 \\
\hline \multirow{2}{*}{ What type of latrine } & Traditional Pit Latrine & $346(82.2)$ & $352(83.8)$ & 1 & 1 \\
\hline & Open field defecation & $75(17.8)$ & $68(16.2)$ & $.891(.622,1.278)$ & $.732(.473,1.183)$ \\
\hline \multirow{2}{*}{$\begin{array}{l}\text { Wash hands before and } \\
\text { after feeding child* }\end{array}$} & Yes & $418(99.3)$ & $420(100)$ & & \\
\hline & No & $3(0.7)$ & $(0)$ & & \\
\hline
\end{tabular}

*The variables cannot be computed in statistical analysis as some of their categories are $<5 \%$

\subsection{Dietary Diversity Score Characteristics}

More than half of the food secure and food insecure households $243(57.7 \%)$ and 220(52.4\%) had have high household dietary diversity score, respectively. As to individual dietary diversity score, majority of children 372 $(88.4 \%)$ and $365(86.9 \%)$ from both food secure and food insecure households had have high individual dietary diversity score, respectively.

\subsection{Prevalence of Under Nutrition (Stunting, Underweight and Wasting) of 6 Months to 5 Years of Age Children}

The magnitude of stunting was higher in the children of 
food insecure households $(52.1 \%, 95 \% \mathrm{CI}: 43.1,52.4)$ compared to child stunting from food secure households (46.1\%, 95\%CI: 41.1, 51.1). Similarly, the prevalence of underweight was higher in the children from food insecure households (21\%, 95\%CI: 17.1, 24.8) compared to child underweight from the food secure households (18.1\%, 95\%CI: 14.7, 21.6). Child wasting was also higher in the children of food insecure households compared to the children from the food secure households $(12.6 \%, 95 \% \mathrm{CI}$ : 9.8, 16.2 Vs 7.1\% 95\%CI: 4.8, 9.7), respectively.

\subsection{Associated factors of Under Nutrition (Stunting, Underweight, Wasting)}

Bivariate and multivariable analysis was done to establish association among the independent variables and nutritional outcome variables. Independent variables with $p$-value $<0.25$ in the bivariate analysis were included in the final multivariate analysis and significance was decided at $\mathrm{p}$-value $<0.05$ and AOR 95\%CI)

\subsubsection{Associated Factors of Child Stunting}

Three variables namely occupation of the father, family head and duration of continued breastfeeding were found to be significantly associated with child stunting in children from the food secure households. Similarly, age of the child, head of the family, and duration of continued breast feeding had statistically significant association with child stunting from the food insecure households (table 5).

Table 5. Associated factors of stunting in under five children from food secure and food insecure households of rural communities of Saesie Tsaeda Emba District, Eastern Tigray zone, $2014(n 1=421, n 2=420)$.

\begin{tabular}{|c|c|c|c|c|}
\hline \multirow{3}{*}{ Variables } & \multicolumn{4}{|l|}{ Stunting } \\
\hline & \multicolumn{4}{|c|}{ Food secure HHs $(n=421)$} \\
\hline & No, N (\%) & Yes, N (\%) & COR(95\% CI) & $\operatorname{AOR}(95 \% \mathrm{CI})$ \\
\hline \multicolumn{5}{|l|}{ Age of child } \\
\hline 6-24 months & $140(56.2)$ & $109(43.8)$ & $.790(.534,1.167)^{*}$ & $.847(.501,1.431)$ \\
\hline$\geq 25$ months & $87(50.6)$ & $85(49.4)$ & 1 & 1 \\
\hline \multicolumn{5}{|l|}{ Marital status of mother } \\
\hline Married & $198(54.7)$ & $164(45.3)$ & $*$ & \\
\hline Divorced & $25(46.3)$ & $29(53.7)$ & $*$ & \\
\hline Others(single,widowed) & $4(80)$ & $1(20)$ & $\nLeftarrow$ & \\
\hline \multicolumn{5}{|l|}{ Educational level of mother } \\
\hline Unable to read and Write & $137(55.2)$ & $111(44.8)$ & 1 & 1 \\
\hline able to read and write & $72(59)$ & $50(41)$ & $.857(.552,1.330)$ & $1.102(.616,1.974)$ \\
\hline Elementary School \& above & $18(35.3)$ & $33(64.7)$ & $2.263(1.209,4.234)^{*}$ & $1.250(.441,3.539)$ \\
\hline \multicolumn{5}{|l|}{ Educational level of father } \\
\hline Unable to read and Write & $40(47.1)$ & $45(52.9)$ & 1 & 1 \\
\hline Able to read and write & $136(64.8)$ & $74(35.2)$ & $.530(.334, .840)^{*}$ & $.555(.296,1.042)$ \\
\hline Elementary School \& above & $21(31.3)$ & $46(68.7)$ & $1.940(1.040,3.621)^{*}$ & $1.270(.471,3.424)$ \\
\hline \multicolumn{5}{|l|}{ Occupational status father } \\
\hline Daily labourer & $38(77.6)$ & $11(22.4)$ & 1 & 1 \\
\hline Farmer & $138(51.9)$ & $128(48.1)$ & $2.446(1.359,4.402)^{*}$ & $3.757(1.431,9.864)^{* *}$ \\
\hline Others(herders,merchants) & $20(42.5)$ & $27(57.5)$ & $3.323(1.525,7.243)^{*}$ & $3.506(1.178,10.431)^{* *}$ \\
\hline \multicolumn{5}{|l|}{ Head of family } \\
\hline Father & $34(44.2)$ & $43(55.8)$ & 1 & 1 \\
\hline Mother & $193(56.1)$ & $151(43.9)$ & $.619(.376,1.018)^{*}$ & $.278(.097, .793)^{* *}$ \\
\hline \multicolumn{5}{|c|}{ How many months BF the child } \\
\hline$<1$ year & $8(29.6)$ & $19(70.4)$ & 1 & 1 \\
\hline $1-2$ years & $123(45.9)$ & $145(54.1)$ & $.496(.210,1.173)^{*}$ & $.322(.114, .907)^{* *}$ \\
\hline$>=2$ years & $96(76.2)$ & $30(23.8)$ & $.132(.052, .331)^{*}$ & $.125(.036, .434)^{* *}$ \\
\hline \multicolumn{5}{|c|}{ Child weighedinthe last 3 months } \\
\hline Yes & $178(50.7)$ & $173(49.3)$ & $2.268(1.305,3.940)^{*}$ & $1.277(.625,2.611)$ \\
\hline No & $49(70)$ & $21(30)$ & 1 & 1 \\
\hline \multicolumn{5}{|l|}{ Main source of water } \\
\hline Protected well/Spring & $18(56.2)$ & $14(43.8)$ & $.783(.376,1.630)$ & $1.095(.447,2.681)$ \\
\hline Unprotected well/Spring & $44(77.2)$ & $13(22.8)$ & $.297(.154, .574)^{*}$ & $.794(.336,1.874)$ \\
\hline River water & $10(43.5)$ & $13(56.5)$ & $1.308(.557,3.074)$ & $1.071(.379,3.026)$ \\
\hline Pipe(tap) & $155(50.2)$ & $154(49.8)$ & 1 & 1 \\
\hline \multicolumn{5}{|l|}{ HDDS } \\
\hline High HDDS & $144(59.3)$ & $99(40.7)$ & 1 & 1 \\
\hline Low HDDS & $83(46.6)$ & $95(53.4)$ & $1.665(1.127,2.459)^{*}$ & $1.131(.657,1.950)$ \\
\hline \multicolumn{5}{|l|}{ IDDS } \\
\hline High IDDS & $206(55.4)$ & $166(44.6)$ & 1 & 1 \\
\hline Low IDDS & $21(42.9)$ & $28(57.1)$ & $1.655(.907,3.020)^{*}$ & $1.755(.798,3.862)$ \\
\hline
\end{tabular}


Table 5. (Continue)

\begin{tabular}{|c|c|c|c|c|}
\hline \multirow{3}{*}{ Variables } & \multicolumn{4}{|l|}{ Stunting } \\
\hline & \multicolumn{4}{|c|}{ Food insecure HHs $(n=420)$} \\
\hline & No, $\mathbf{N}(\%)$ & Yes, N (\%) & $\operatorname{COR}(95 \% \mathrm{CI})$ & $\operatorname{AOR}(95 \% \mathrm{CI})$ \\
\hline \multicolumn{5}{|l|}{ Age of child } \\
\hline 6-24 months & $104(44.6)$ & $129(55.4)$ & $1.337(.909,1.967)^{*}$ & $1.636(1.004,2.668)^{* *}$ \\
\hline$\geq 25$ months & $97(51.9)$ & $90(48.1)$ & 1 & 1 \\
\hline \multicolumn{5}{|l|}{ Marital status of mother } \\
\hline Married & $177(49.7)$ & $179(50.3)$ & 1 & 1 \\
\hline Divorced & $22(40)$ & $33(60)$ & $1.483(.832,2.644)^{*}$ & $.290(.015,5.691)$ \\
\hline Others(single,widowed) & $2(22.2)$ & $7(77.8)$ & $3.461(.709,16.889)^{*}$ & ------- \\
\hline \multicolumn{5}{|l|}{ Educational level of mother } \\
\hline Unable to read and Write & $137(51.1)$ & $131(48.9)$ & 1 & 1 \\
\hline able to read and write & $50(44.6)$ & $62(55.4)$ & $1.297(.833,2.019)^{*}$ & $.978(.562,1.700)$ \\
\hline Elementary School \& above & $14(35)$ & $26(65)$ & $1.942(.972,3.882)^{*}$ & $1.276(.442,3.681)$ \\
\hline \multicolumn{5}{|l|}{ Educational level of father } \\
\hline Unable to read and Write & $33(55)$ & $27(45)$ & 1 & 1 \\
\hline Able to read and write & $123(50.6)$ & $120(49.4)$ & $1.053(.655,1.695)$ & $1.090(.580,2.048)$ \\
\hline Elementary School \& above & $20(37.8)$ & $33(62.2)$ & $1.689(.872,3.271)^{*}$ & $1.317(.480,3.620)$ \\
\hline \multicolumn{5}{|l|}{ Occupational status father } \\
\hline Daily labourer & 19(55.9) & $15(44.1)$ & 1 & 1 \\
\hline Farmer & $142(52.2)$ & $130(47.8)$ & $.780(.430,1.414)$ & $1.131(.491,2.602)$ \\
\hline Others(herders,merchants) & $16(32)$ & $34(68)$ & $1.729(.796,3.758)^{*}$ & $2.285(.811,6.436)$ \\
\hline \multicolumn{5}{|l|}{ Head of family } \\
\hline Father & $32(37.2)$ & $54(62.8)$ & 1 & 1 \\
\hline Mother & $169(50.6)$ & $165(49.4)$ & $.579(.356, .942)^{*}$ & $.435(.191, .994)^{* *}$ \\
\hline \multicolumn{5}{|l|}{ How many months BF the child } \\
\hline$<1$ year & $8(29.6)$ & $19(70.4)$ & 1 & 1 \\
\hline $1-2$ years & $100(40.3)$ & $148(59.7)$ & $.623(.623,1.479)^{*}$ & $.405(.232, .708)^{* *}$ \\
\hline$>=2$ years & 93(64.1) & $52(35.9)$ & $.235(.096, .575)^{*}$ & $1.287 .482,3.436)$ \\
\hline \multicolumn{5}{|c|}{ Child weighedinthe last 3 months } \\
\hline Yes & $149(44.6)$ & $185(55.4)$ & $\star$ & \\
\hline No & $52(60.5)$ & $34(39.5)$ & $*$ & \\
\hline \multicolumn{5}{|l|}{ Main source of water } \\
\hline Protected well/Spring & $15(55.6)$ & $12(44.5)$ & $*$ & \\
\hline Unprotected well/Spring & $44(68.8)$ & $22(31.2)$ & $*$ & \\
\hline River water & $6(21.4)$ & $22(78.6)$ & $*$ & \\
\hline Pipe(tap) & $136(45.2)$ & $165(54.8)$ & $*$ & \\
\hline \multicolumn{5}{|l|}{ HDDS } \\
\hline High HDDS & $105(47.7)$ & $115(52.3)$ & $*$ & \\
\hline Low HDDS & $96(48)$ & $104(52)$ & $*$ & \\
\hline \multicolumn{5}{|l|}{ IDDS } \\
\hline High IDDS & $169(46.3)$ & $196(53.7)$ & $*$ & \\
\hline Low IDDS & $32(58.2)$ & $23(41.8)$ & $*$ & \\
\hline
\end{tabular}

$*$ P-value $<0.25$ in the bivariate analysis

** P-value $<0.05$ in the multivariable analysis

* Indicated independent variables which were not candidates either in food secure or food insecure households

\subsubsection{Associated Factors of Child Underweight}

Three variables i.e. educational status of father, sex of the child, and current breast feeding status of the child were the factors associated with underweight for children from food secure households. Correspondingly, age of mother, occupational status of father, sex of child, $1^{\text {st }}$ complementary food given to the child, and main source of water to the household were the main predictors of underweight in the food insecure households (table 6). 
Table 6. Associated factors of underweight in children from food secure and food insecure households of rural communities of Saesie Tsaeda Emba District, Eastern Tigray zone, $2014(n 1=421, n 2=420)$.

\begin{tabular}{|c|c|c|c|c|}
\hline \multirow{3}{*}{ Variables } & \multicolumn{4}{|c|}{ Underweight } \\
\hline & \multicolumn{4}{|c|}{ Food secure HHs( $n=421)$} \\
\hline & No, N (\%) & Yes, $N(\%)$ & COR( $95 \%$ CI & $\operatorname{AOR}(95 \%$ CI \\
\hline \multicolumn{5}{|l|}{ Age of child } \\
\hline 6-24 months & $208(83.5)$ & $41(16.5)$ & & $*$ \\
\hline$\geq 25$ months & 137(79.7) & $35(20.3)$ & & $*$ \\
\hline \multicolumn{5}{|l|}{ Educational level of mother } \\
\hline Unable to read and Write & 218(87.9) & $30(12.1)$ & 1 & 1 \\
\hline able to read and write & $100(82)$ & $22(18)$ & $1.599(.878,2.910)^{*}$ & $1.357(.657,2.800)$ \\
\hline Elementary School \& above & $27(52.9)$ & $24(47.1)$ & $6.459(3.307,12.615)^{*}$ & $1.135(.401,3.217)$ \\
\hline \multicolumn{5}{|l|}{ Educational level of father } \\
\hline Unable to read and Write & $72(84.7)$ & $13(15.3)$ & 1 & 1 \\
\hline Able to read and write & $190(90.5)$ & $20(9.5)$ & $.435(.226, .837)^{*}$ & $.261(.119, .573)^{* *}$ \\
\hline Elementary School \& above & $33(49.3)$ & $34(50.7)$ & $3.892(1.990,7.614)^{*}$ & $2.608(.989,6.875)$ \\
\hline \multicolumn{5}{|l|}{ Occupational status father } \\
\hline Daily labourer & $38(77.6)$ & $11(22.4)$ & & $*$ \\
\hline Farmer & $216(81.2)$ & $50(18.8)$ & & $*$ \\
\hline Others(herders, merchants) & $41(87.2)$ & $6(12.8)$ & & $*$ \\
\hline \multicolumn{5}{|l|}{ No of individuals in $\mathrm{HH}$} \\
\hline$<5$ & $125(76.7)$ & $38(23.3)$ & 1 & 1 \\
\hline$\geq 5$ & $220(81.3)$ & $38(18.7)$ & $.568(.344, .937)^{*}$ & $.499(.239,1.042)$ \\
\hline \multicolumn{5}{|l|}{ Sex of the study child } \\
\hline Female & $186(86.1)$ & $30(13.9)$ & 1 & 1 \\
\hline Male & $159(77.6)$ & $46(22.4)$ & $1.794(1.081,2.976)^{*}$ & $2.236(1.236,4.044)^{* *}$ \\
\hline \multicolumn{5}{|l|}{ How frequent $\mathrm{BF}$ the child } \\
\hline$\geq 8$ times & $339(82.3)$ & 73(17.7) & 1 & 1 \\
\hline Others $(<8 \mathrm{x}$, only when cries) & $6(66.7)$ & $3(33.3)$ & $.431(.105,1.762)^{*}$ & $3.635(.502,26.322)$ \\
\hline \multicolumn{5}{|l|}{ How many months $\mathrm{BF}$ the child } \\
\hline$<1$ year & $20(74.1)$ & $7(25.9)$ & 1 & 1 \\
\hline $1-2$ years & 214(79.9) & $54(20.1)$ & $.496(.210,1.173)^{*}$ & $1.155(.350,3.815)$ \\
\hline$>=2$ years & $111(88.1)$ & $15(11.9)$ & $.132(.052, .331)^{*}$ & $1.245(.297,5.229)$ \\
\hline \multicolumn{5}{|l|}{ Current BF status of the child } \\
\hline Partial Breastfeeding & $222(83.8)$ & $43(16.2)$ & $.722(.436,1.195)^{*}$ & $.385(.160, .925)^{* *}$ \\
\hline Not Breastfeeding & $123(78.8)$ & $33(21.2)$ & 1 & 1 \\
\hline \multicolumn{5}{|l|}{ First complementary food } \\
\hline Milk & $96(91.4)$ & $9(8.6)$ & $*$ & \\
\hline Adult Food & $26(89.7)$ & $3(10.3)$ & $*$ & \\
\hline Porridge & $223(77.7)$ & $64(22.3)$ & $*$ & \\
\hline \multicolumn{5}{|l|}{ Place of birth for this child } \\
\hline Home & $106(79.7)$ & $27(20.3)$ & $*$ & \\
\hline Health Facility & $239(83)$ & $49(17)$ & $*$ & \\
\hline \multicolumn{5}{|c|}{ Childweighedin the last 3 months } \\
\hline Yes & 283(80.6) & $68(19.4)$ & $1.862(.852,4.072)^{*}$ & $1.494(.574,3.887)$ \\
\hline No & $62(88.6)$ & $8(11.4)$ & 1 & 1 \\
\hline \multicolumn{5}{|c|}{ Did the child sick in last 2 weeks } \\
\hline Yes & $57(81.4)$ & 13(18.6) & & \\
\hline No & $288(82.1)$ & $63(17.9)$ & & \\
\hline \multicolumn{5}{|l|}{ Main source of water } \\
\hline Protected well/Spring & $26(81.2)$ & $6(18.8)$ & $1.141(.447,2.909)$ & $.892(.307,2.595)$ \\
\hline Unprotected well/Spring & $47(82.5)$ & $10(17.5)$ & $1.052(.499,2.215)$ & $2.607(.882,7.703)$ \\
\hline River water & $15(65.2)$ & $8(34.8)$ & $2.636(1.063,6.538)^{*}$ & $2.203(.730,6.647)$ \\
\hline Pipe(tap) & $257(83.2)$ & $52(16.8)$ & 1 & 1 \\
\hline \multicolumn{5}{|l|}{ What type of latrine } \\
\hline Traditional Pit Latrine & $279(80.6)$ & $67(19.4)$ & 1 & 1 \\
\hline Open field defecation & $66(88)$ & $9(12)$ & $.568(.269,1.197)^{*}$ & $.838(.345,2.038)$ \\
\hline
\end{tabular}


Table 6. (Continue)

\begin{tabular}{|c|c|c|c|c|}
\hline \multirow{3}{*}{ Variables } & \multicolumn{4}{|c|}{ Underweight } \\
\hline & \multicolumn{4}{|c|}{ Food insecure HHs $(n=420)$} \\
\hline & No, N (\%) & Yes, $N(\%)$ & COR(95\% CI & AOR(95\% CI \\
\hline \multicolumn{5}{|l|}{ Age of child } \\
\hline 6-24 months & $189(81.1)$ & $44(18.9)$ & $.757(.472,1.212)^{*}$ & $.780(.393,1.548)$ \\
\hline$\geq 25$ months & $143(72.5)$ & $44(23.5)$ & 1 & 1 \\
\hline \multicolumn{5}{|l|}{ Educational level of mother } \\
\hline Unable to read and Write & $225(84)$ & $43(16)$ & 1 & 1 \\
\hline able to read and write & $90(80.4)$ & $22(19.6)$ & $1.279(.724,2.259)$ & $.868(.420,1.792)$ \\
\hline Elementary School \& above & $17(42.5)$ & $23(57.5)$ & $7.079(3.492,14.352) *$ & $1.128(.392,3.247)$ \\
\hline \multicolumn{5}{|l|}{ Educational level of father } \\
\hline Unable to read and Write & $47(78.3)$ & 13(21.7) & 1 & 1 \\
\hline Able to read and write & $210(86.7)$ & $33(13.6)$ & $.727(.382,1.385)$ & $.643(.312,1.328)$ \\
\hline Elementary School \& above & $20(37.8)$ & $33(62.2)$ & $6.750(3.212,14.187)^{*}$ & $2.558 .923,7.090)$ \\
\hline \multicolumn{5}{|l|}{ Occupational status father } \\
\hline Daily labourer & $22(64.7)$ & $12(35.3)$ & 1 & 1 \\
\hline Farmer & $206(75.7)$ & $66(24.3)$ & $.638(.334,1.220)^{*}$ & $.497(.223,1.110)$ \\
\hline Others(herders, merchants) & $48(96)$ & $2(4)$ & $.077(.017, .354)^{*}$ & $.118(.022, .631)^{* *}$ \\
\hline \multicolumn{5}{|l|}{ No of individuals in $\mathrm{HH}$} \\
\hline$<5$ & $107(77)$ & $32(23)$ & $*$ & \\
\hline$\geq 5$ & $225(80.1)$ & $56(19.9)$ & 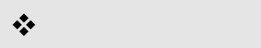 & \\
\hline \multicolumn{5}{|l|}{ Sex of the study child } \\
\hline Female & $187(84.6)$ & $34(15.4)$ & 1 & 1 \\
\hline Male & $145(72.9)$ & $54(27.1)$ & $2.048(1.266,3.313)^{*}$ & $1.789(1.023,3.127)^{* *}$ \\
\hline \multicolumn{5}{|l|}{ How frequent $\mathrm{BF}$ the child } \\
\hline$\geq 8$ times & $7(63.6)$ & $4(36.4)$ & $*$ & \\
\hline Others $(<8 \mathrm{x}$, only when cries) & $197(79.4)$ & $51(20.6)$ & $*$ & \\
\hline \multicolumn{5}{|l|}{ How many months $\mathrm{BF}$ the child } \\
\hline$<1$ year & $22(81.5)$ & $5(18.5)$ & $*$ & \\
\hline $1-2$ years & $197(79.4)$ & $51(20.6)$ & $*$ & \\
\hline$>=2$ years & $113(77.9)$ & $32(22.1)$ & $*$ & \\
\hline \multicolumn{5}{|l|}{ Current BF status of the child } \\
\hline Partial Breastfeeding & $212(81.5)$ & $48(18.5)$ & $*$ & \\
\hline \multirow{2}{*}{\multicolumn{5}{|c|}{$\begin{array}{l}\text { Not Breastfeeding } \\
\text { First complementary food }\end{array}$}} \\
\hline & & & & \\
\hline Milk & $91(96.8)$ & $3(3.2)$ & $.084(.026, .272)^{*}$ & $.157(.045, .552)^{* *}$ \\
\hline Adult Food & $30(93.8)$ & $2(6.2)$ & $.169(.040, .725)^{*}$ & $.239(.050,1.145)$ \\
\hline Porridge & $211(71.8)$ & $83(28.2)$ & 1 & 1 \\
\hline \multicolumn{5}{|l|}{ Place of birth for this child } \\
\hline Home & $106(73.1)$ & $39(26.9)$ & $1.697(1.050,2.742)^{*}$ & $1.748(.904,3.378)$ \\
\hline Health Facility & $226(82.2)$ & $49(17.8)$ & 1 & 1 \\
\hline \multicolumn{5}{|c|}{ Childweighedin the last 3 months } \\
\hline Yes & $261(78.1)$ & $73(21.9)$ & $*$ & \\
\hline No & $71(82.6)$ & $15(17.8)$ & $*$ & \\
\hline \multicolumn{5}{|c|}{ Did the child sick in last 2 weeks } \\
\hline Yes & $76(85.4)$ & $13(14.6)$ & $.584(.307,1.110)^{*}$ & $1.826(.886,3.766)$ \\
\hline No & $256(77.3)$ & $75(22.7)$ & 1 & 1 \\
\hline \multicolumn{5}{|l|}{ Main source of water } \\
\hline Protected well/Spring & $17(63)$ & $10(37)$ & $3.100(1.339,7.181)^{*}$ & $1.390(.523,3.696)$ \\
\hline Unprotected well/Spring & $49(76.6)$ & $15(23.4)$ & $1.614(.838,3.108)^{*}$ & $1.108(.516,2.379)$ \\
\hline River water & $13(46.4)$ & $15(53.6)$ & $6.082(2.721,13.593) *$ & $2.754(1.068 .7 .098)^{* *}$ \\
\hline Pipe(tap) & $253(84.1)$ & $48(15.9)$ & 1 & 1 \\
\hline \multicolumn{5}{|l|}{ What type of latrine } \\
\hline Traditional Pit Latrine & $280(79.5)$ & $72(20.5)$ & $\nLeftarrow$ & \\
\hline Open field defecation & $52(76.5)$ & $16(23.5)$ & $*$ & \\
\hline
\end{tabular}

* Indicated independent variables which were not candidates either in FS or FI HHs $\quad *$ P-value $<0.25$ in the bivariate analysis ** P-value $<0.05$ in the multivariate analysis

\subsubsection{Associated Factors of Child Wasting}

The final predictors of child wasting in the food secure households were age of the father and number of cattle owned by the household. Likewise, age of child and main source of water to the household were the factors associated with child wasting from the food insecure households (table 7). 
Table 7. Associated factors of wasting in children from food secure and food insecure households of rural communities of Saesie Tsaeda Emba District, Eastern Tigray zone, $2014(n 1=421, n 2=420)$.

\begin{tabular}{|c|c|c|c|c|}
\hline \multirow{3}{*}{ Variables } & \multicolumn{4}{|c|}{ Wasting } \\
\hline & \multicolumn{4}{|c|}{ Food secure HHs( $(n=421)$} \\
\hline & No, N (\%) & Yes, $N(\%)$ & $\operatorname{COR}(95 \% \mathrm{CI})$ & $\operatorname{AOR}(95 \% \mathrm{CI})$ \\
\hline \multicolumn{5}{|l|}{ Age of child } \\
\hline 6-24 months & $236(94.8)$ & $13(5.2)$ & $.504(.238,1.068)^{*}$ & $.486(.199,1.186)$ \\
\hline$\geq 25$ months & $155(90.1)$ & $17(9.9)$ & 1 & 1 \\
\hline \multicolumn{5}{|l|}{ Occupational status father } \\
\hline Daily laborer & $44(89.8)$ & $5(10.2)$ & 1 & 1 \\
\hline Farmer & $244(91.7)$ & $22(8.3)$ & $1.021(.375,2.784)$ & $.817(.212,3.156)$ \\
\hline Others(herders, merchants) & $46(97.9)$ & $1(2.1)$ & $.245(.028,2.166)^{*}$ & $.250(.027,2.344)$ \\
\hline \multicolumn{5}{|l|}{ No of cattle owned by HH } \\
\hline No cattle & $117(90.7)$ & $12(9.3)$ & 1 & 1 \\
\hline Only one & $68(89.5)$ & $8(10.5)$ & $1.147(.447,2.946)$ & $.275(.073,1.030)$ \\
\hline$\geq 2$ & $206(95.4)$ & $10(4.6)$ & $.473(.198,1.129)^{*}$ & $.169(.048, .596)^{* *}$ \\
\hline \multicolumn{5}{|c|}{ Child weighed in the last 3 months } \\
\hline Yes & $330(94)$ & $21(6)$ & 1 & 1 \\
\hline No & $61(87.1)$ & $9(12.9)$ & $2.319(1.014,5.303)^{*}$ & $.938(.352,2.503)$ \\
\hline \multicolumn{5}{|c|}{ Did the child sick in last 2 weeks } \\
\hline Yes & $65(92.9)$ & $5(7.1)$ & $1.003(.370,2.717)$ & \\
\hline No & $326(92.9)$ & $25(7.1)$ & 1 & \\
\hline \multicolumn{5}{|l|}{ Main source of water } \\
\hline Protected well/Spring & $29(90.6)$ & $3(9.4)$ & $*$ & \\
\hline Unprotected well/Spring & $51(89.5)$ & $6(10.5)$ & $*$ & \\
\hline River water & $22(95.7)$ & $1(4.3)$ & $*$ & \\
\hline Pipe(tap) & $289(93.5)$ & $20(6.5)$ & $*$ & \\
\hline \multicolumn{5}{|l|}{ HDDS } \\
\hline High HDDS & $221(90.9)$ & $22(9.1)$ & 1 & 1 \\
\hline Low HDDS & $170(95.5)$ & $8(4.5)$ & $.473(.205,1.088)^{*}$ & $.622(.223,1.733)$ \\
\hline \multicolumn{5}{|l|}{ IDDS } \\
\hline High IDDS & $348(93.5)$ & $24(6.5)$ & 1 & 1 \\
\hline Low IDDS & $43(87.8)$ & $6(12.2)$ & $2.023(.783,5.227)^{*}$ & $2.429(.764,7.724)$ \\
\hline
\end{tabular}

Table 7. (Continue)

\begin{tabular}{|c|c|c|c|c|}
\hline \multirow{3}{*}{ Variables } & \multicolumn{4}{|l|}{ Wasting } \\
\hline & \multicolumn{4}{|c|}{ Food insecure HHs $(n=420)$} \\
\hline & No, $N(\%)$ & Yes, N (\%) & COR(95\% CI) & $\operatorname{AOR}(95 \% \mathrm{CI})$ \\
\hline \multicolumn{5}{|l|}{ Age of child } \\
\hline 6-24 months & $210(90.1)$ & 23(9.9) & $.573(.321,1.025)^{*}$ & $.479(.239, .961)^{* *}$ \\
\hline$\geq 25$ months & $157(84)$ & $30(16)$ & 1 & 1 \\
\hline \multicolumn{5}{|l|}{ Occupational status father } \\
\hline Daily laborer & $26(76.5)$ & $8(23.5)$ & $*$ & \\
\hline Farmer & $232(85.3)$ & $44(14.7)$ & $*$ & \\
\hline Others(herders, merchants) & $49(98)$ & $1(2)$ & $*$ & \\
\hline \multicolumn{5}{|l|}{ No of cattle owned by HH } \\
\hline No cattle & $112(86.8)$ & $17(13.2)$ & 1 & 1 \\
\hline Only one & $62(76.5)$ & $19(23.5)$ & $2.019(.979,4.165) *$ & $1.422(.623,3.248)$ \\
\hline$\geq 2$ & 193(91.9) & $17(8.1)$ & $.580(.285,1.182)^{*}$ & $1.798(.759,4.257)$ \\
\hline \multicolumn{5}{|c|}{ Child weighed in the last 3 months } \\
\hline Yes & 297(88.9) & $37(11.1)$ & 1 & 1 \\
\hline No & $70(81.4)$ & $16(18.6)$ & $1.835(.966,3.485)^{*}$ & $1.004(.464,2.171)$ \\
\hline \multicolumn{5}{|c|}{ Did the child sick in last 2 weeks } \\
\hline Yes & $81(91)$ & $8(9)$ & $.628(.284,1.385)^{*}$ & $.591(.245,1.427)$ \\
\hline No & $286(86.4)$ & $45(13.6)$ & 1 & 1 \\
\hline \multicolumn{5}{|l|}{ Main source of water } \\
\hline Protected well/Spring & $21(77.8)$ & $6(22.2)$ & $3.154(1.166,8.535)^{*}$ & $2.959(1.042,8.399)^{* *}$ \\
\hline Unprotected well/Spring & $44(68.8)$ & $20(31.2)$ & $5.018(2.572,9.792) *$ & $3.541(1.552,8.083)^{* *}$ \\
\hline River water & 26(92.9) & $2(7.1)$ & $.849(.190,3.788)$ & $.813(.171,3.866)$ \\
\hline Pipe(tap) & $276(91.7)$ & $25(8.3)$ & 1 & 1 \\
\hline HDDS & & & & \\
\hline
\end{tabular}




\begin{tabular}{|c|c|c|c|c|}
\hline \multirow{3}{*}{ Variables } & \multicolumn{4}{|l|}{ Wasting } \\
\hline & \multicolumn{4}{|c|}{ Food insecure HHs $(n=420)$} \\
\hline & No, N (\%) & Yes, N (\%) & COR(95\% CI) & $\operatorname{AOR}(95 \% \mathrm{CI})$ \\
\hline High HDDS & $1829(82.7)$ & $38(17.3)$ & 1 & 1 \\
\hline Low HDDS & $185(92.5)$ & $15(7.5)$ & $.388(.206, .730)^{*}$ & $.686(.340,1.383)$ \\
\hline \multicolumn{5}{|l|}{ IDDS } \\
\hline High IDDS & $321(87.9)$ & $44(12.1)$ & 1 & \\
\hline Low IDDS & $46(83.6)$ & $9(16.4)$ & $1.427(.654,3.116)$ & \\
\hline
\end{tabular}

* P-value $<0.25$ in the bivariate analysis ** $\mathrm{P}$-value $<0.05$ in the multivariate analysis

* Indicated independent variables which were not candidates either in food secure or food insecure households

\section{Discussion}

The aim of this study was to assess and compare the anthropometric nutritional status and associated factors of 6 months to 5 years old children from food secure and food insecure households of rural communities in Saesie Tsaeda EmbaDistrict.

As a result, very high prevalence of malnutrition (stunting, under weight, and wasting) was observed among children of food secure and food insecure households.

\subsection{Stunting}

The prevalence of stunting in children from the food insecure and food secure households was $52.1 \%$ and $46.1 \%$, respectively. And this revealed that there was statistically significant difference between the comparison groups in which the children from food insecure households were about $48 \%$ at higher risk to be stunted when compared to the children of food secure households. Dependable with this, a study in Ghana revealed that compared to children in food insecure households, children in secure households were $46 \%$ protected from chronic malnutrition.

Result of the current study revealed higher prevalence of stunting from the food insecure households compared to the cross-sectional study conducted from Tigray where $42.7 \%$ of the children were stunted (14). This could partly be explained by the differences in sample size, residential areas and food security status of the study communities. In a community based cross-sectional study in children of food insecure households of North Showa zone (11), the prevalence of stunting was $54.2 \%$ which was comparable to the prevalence of stunting in the food insecure households of our study communities but higher than that of the food secure households. And this could be an indication that being food secure is a way to be less malnourished.

Occupation of father, head of family, and duration of continued breast feeding were the factors associated with stunting in food secure households. Whereas age of the child, head of family, and duration of continued breast feeding the important determinant factors for stunting in children from the food insecure households.

As to studies in Nigeria $(16,17)$ there was no statistical significant association between the occupation of father and stunting. But, in the current study children of farmers and others (herders \& others) were 3.75 and 3.5 times at higher risk to be stunted when compared to children of daily laborer fathers respectively in the food secure households. This can be argued as the fact that those farmers and herders, even though they produce varied types of cereals and animal products, they may not use it for their household consumption; rather they use it for market sell in order to get money. So, this kind of event in the long run may cause their family members particularly the children to be malnourished. Children of mother headed family were $72.2 \%$ and $56.5 \%$ at reduced risk to be stunted when compared to children of father headed family in both food secure and food insecure households respectively; in which this was consistent to a study in Tanzania (15) that revealed a woman's decision making autonomy over her own cash earnings is found to be protective against any form of malnutrition to the children. This could be then due to the fact that mothers are the center for enhancing most nutrition activities within households being as caretaker, food provider, and navigators of the cultural information. So, when family is headed by women themselves, children's nutritional status is better, even in a very poor household. On the other hand, the finding of this current study was in contrast with the finding of a study in Afar (18) which stated that children of female headed family were at higher risk to be malnourished.

Breast-feeding has been known to be the best traditional way to feed infants. Length of breast-feeding beyond 12 months is substantial interval of avoiding pregnancy. And breast-feeding may play a role in lengthening an ovulation while the introduction of supplementary food is often associated with more rapid return of ovulation. Compounded with the above situation, the early child detachment from breast-feeding significantly affects the health and nutritional status of the child through reduction of care and exposing the child to early weaning, which in turn increases the risk of diarrheal diseases and nutritional deficiencies (15, 19). Steady with this fact, in the current study it was found that the longer the duration of breast feeding the less risk of stunting to the children in both comparative groups in which children who breast fed for $1-2$ years and $\geq 2$ years were $67.8 \%$ and $87.5 \%$ at reduced risk to be stunted in the food secure households respectively; and those who breast fed for 1-2 years in the food insecure households were $59.5 \%$ at reduced risk to be stunted; all these compared to those who breast fed $<1$ year of duration. But, this finding was in contradiction with the finding of a study in West Gojam zone (10) which revealed that duration of breast milk was the risk factor for stunting that children who were breastfed more than 2 years paradoxical were at high risk of stunting. 
Children aged $6-23$ months of age contribute more to the overall under-5 stunting levels than those 24 months and above. Stunting is also passed on between generations: stunted mothers tend to have children with low birth weight, who are likely to remain stunted. Because of their increased nutrition needs and greater vulnerability between conception and 2 years of age, lack of access to an adequate diet for a couple of months or more deprives children of essential nutrients, leading to micronutrient deficiencies, constrained development and stunting. Once the children reach 2 years of age, most of this damage cannot be undone $(10,15)$. In consistent to the findings of these studies, in the current study children aged 624 months were $63.6 \%$ at increased risk to be stunted when compared to children of age $\geq 25$ months of age in the food insecure households alone. The increased risk of under nutrition as children reach their second year of life may be due to a combination of interactive effects. During this period, growth and nutritional status may be affected as children are being weaned from the breast. Not only do mothers lose their ability to produce enough milk to meet the nutritional demand of the growing infant, children at this age are also losing the passive immunity received from the mother (20). Furthermore, other studies indicated that stunting increased in the likelihood as the age of the child increased which seem to be in support of the above findings $(21,17)$.

\subsection{Underweight}

Children from the food secure and food insecure households were $18.1 \%$ and $20.5 \%$, underweight respectively. But, there was no statistically significant difference between the comparison groups. The prevalence of underweight in most of the regions was higher (26\%-40.2\%) when compared with the current study's magnitude of underweight in both comparison groups except it was consistent with that of Gambela and Harari (20.3\%- 21.5\%) but much higher than of Addis Ababa (6.4\%) (22).

Educational status of father, sex of the child, and current breast feeding status of the child were the factors associated with underweight for children from food secure households and age of mother, occupational status of father, sex of child, $1^{\text {st }}$ complementary food given to the child, and main source of water to the household were the main predictors of underweight in the food insecure households.

Even though there was no statistically significant association between educational status of father and underweight in different studies in Nigeria $(16,17)$, in the current study, children of those fathers able to read and write were statistical significantly $73.9 \%$ at reduced risk to be underweight when compared to the children of fathers unable to read and write in the food secure households alone. This could be due to the reason that fathers who can read and write can be exposed and updated themselves to reading materials such as broachers, posters and other leaflets concerning about nutritional activities and infant and young child feeding practices; so, they can apply it to their children in order to make their children well nourished. This was also found to be consistent with finding of a study done in Afar
(18). More notably, sex of the child was found to be determinant factor for underweight in which male children were 2.23 times and $78.9 \%$ at increased risk when compared to the female children in both the food secure and food insecure households respectively. And this finding was highly supported by various studies in different regions of the country and other developing countries (15, 23, 24, and 25). And this might be as a reason that the neglect and sex preference imposed to male children by assuming that male children are capable of persisting nutritional harsh conditions and hunger; perhaps caused more attention and care to be given for female children who became then to be in higher nutritional status when compared to male children. However, this could be crucial issue for further and detailed research studies why male children are still at higher risk to be malnourished compared to female children. Furthermore, current breast feeding status of the children was another determinant factor for underweight in children of food secure households alone in which those children who were in partial breast feeding were $61.5 \%$ at reduced risk to be underweight when compared to those children who were not breast fed. This can be strongly argued that optimal infant and young child feeding-initiation of breastfeeding within one hour of birth, exclusive breast-feeding for the first six months of the Child's life and continued breastfeeding until the child is at least 2 years old, together with age-appropriate, nutritionally adequate and safe complementary foods-can have a major impact on child survival, health, brain and motor development. It also has the potential to prevent an estimated 19 percent of all under five deaths in the developing world, more than any other preventive intervention (15). Age of mother was also found to be the determinant factor for underweight in the food insecure households alone, in which as age of mother increased the risk of being underweight for a child decreased by $6.4 \%$ and this was similar to the study in Tanzania (15) in which children of young mothers were at higher risk to be underweight. This could be owed to the fact that young females are at high demand of nutrients and also at higher risk for health related problems due to lack of exposures and experiences to nutrition and health related activities which can make them to be debilitated for themselves. And as a result, they may not care their children so, ended up being malnourished.

Even if an association was not found between occupational status of father and underweight in different studies of Nigeria $(16,17)$, children of others (herders \& others) were $88.2 \%$ at reduced risk to be underweight when compared to children of daily laborer fathers for food insecure households alone. This might be straight forward that those children of herders may more frequently consume animal products and became at reduced risk to be malnourished as more or less their stable foods are animal products.

Household that faces food insecurity has a greater burden when deciding how to ensure that their growing child has a nutrient-dense and appropriate diet. The situation is exacerbated by the introduction of inappropriate complementary foods and reliance on cow's milk or formula, 
which may be contaminated or of poor nutritional quality (26). In addition, intestinal blood lose increased in $30 \%$ of infants fed whole cow's milk but didn't increase in the formula fed group, even though all were previously fed iron-fortified formula were breast -fed in the first 6 months of life; which is then no longer whole cow's milk is recommended in the first 12 months of life (27). However, in the current study it was found that children who began complementary feeding with cow's milk were statistical significantly $84.3 \%$ at reduced risk to be underweight compared to those children who began complementary feeding with porridge in the food insecure households alone. So, this could be again a concern for further researches to know the anemia status of those children and others as cow's milk consumption by infants less than 12 months of age was common practice there though it was shown that cow's milk consumption had protective effect against being underweight. Another determinant factor of underweight in the current study was the main source of water to the household though association was not found in other studies of regions of the country $(23,28)$ and developing countries $(15,16)$; but, in this current study those children of food insecure households who were used to river water as main source were 2.75 times at higher risk to be underweight compared to those children of who were used to pipe (hand pump) as main source of water. And this might be as reasons of poor households were more likely to obtain water from unsafe sources. Where water was not readily available, food hygiene may often inadequate. This again may increase the risk of diarrheal diseases and under nutrition (28).

\subsection{Wasting}

About $7.1 \%$ and $12.6 \%$ of the children from the food secure and food insecure households were wasted respectively. Result of the current study revealed that there was statistically significant difference between the comparison groups in which the children from food insecure households were about 2.4 times at higher risk to be wasted when compared to the children of food secure households. The result was consistent with a study report from Nigeria (26) that food-insecure households were five times more likely than food secure households to have wasted children (COR=5.707, $95 \% \mathrm{CI}=1.31-24.85)$. This could be an indication that being food secure can be a necessary condition to be nutritionally secured in the long run when it is integrated with other short and long route nutrition interventions.

Finally, the factors associated with child wasting in the food secure households were age of the father and number of cattle owned by the household and age of child and main source of water to the household were the factors associated with child wasting from the food insecure households.

Although there was no literature which showed association between age of father and wasting, in the current study for those only children of food secure households as the age of father increased the risk of being wasted for a child was increased by $11 \%$. And this can be argued as the age of fathers increase their working capacity may decrease due to less physical energy and high aging they do face which this again could cause their household be less food self sufficient and food secure. As a result, children in this type of households can end up being malnourished (wasted). More importantly, children of those only food secure households with $\geq 2$ cattle were $83.4 \%$ at reduced risk to be wasted when compared to those children of households with no cattle; which may be related to the nutritional value in which the children may obtain from consumption of animal products. And this was soundly supported by different studies in the country $(11,18$, and 24$)$.

As to the children of food insecure households, there was significant association between the age of the child and wasting in which children aged 6-24 months were 52.1\% at reduced risk to be wasted when compared to children of age $\geq 25$ months; which I can argue that this age group may be benefited from the combined effect of the continuous breast feeding and complementary feeding which they were at reduced risk to be wasted. And this was supported by different studies $(14,26)$ but in contradiction with the studies $(15,23)$. As a final point, children of food insecure households who were used to Protected and unprotected well/Spring as main source of water were 2.95 and 3.54 times at higher risk to be wasted respectively; compared to those children of who were used to pipe (hand pump) as main source of water. And the justification mentioned above for underweight can also work here for this reason.

\section{Conclusion}

In this study, it was observed that child-hood malnutrition among 6 months to 5 years of age children was among the main public health and welfare problem of the population of Saesie Tsaeda Emba District though comparatively children of the food secure households were at better nutritional status in all the nutritional outcome indicators of this study. When compared to the national and regional prevalence of malnutrition, prevalence of stunting and wasting in the children of food insecure households were higher than that of both national and regional (Tigray) prevalence whereas to the children of food secure households it was only stunting which was higher than that of the national prevalence only. And this could be the signal that indicated being food secure is the way which is important to address nutrition security.

More importantly, comparison of the prevalence of the under nutrition of this current study with the targets of national nutrition program 2014/15 of Ethiopia, it was only in prevalence of underweight which promising result was observed in both the comparative groups which was found to be below the NNP 2014/15 target which is $21 \%$. But, the prevalence of both stunting and wasting were found to be far away in a higher magnitude from the targets which are $30 \%$ and 3\% for both stunting and wasting, respectively in both the comparative groups. This will be then an alarming message to all the nutrition sensitive sectors and other concerned bodies that all have a long way to go; to address both the chronic and acute under nutrition of the population. 


\section{Acknowledgements}

We are grateful for Save the Children for its financial support in which it made our work be free of financial constraints, smooth and interesting. In addition, we are thankful utmost for Saesie Tsaeda-Emba District health office and Food Security Task Force for all the collaboration during data collection. We are also pleased to all the data collectors and supervisors for their committed and successful work of the data collection.

\section{References}

[1] Hassam et al, assessment of nutritional status of 1-5 year old children in an urban union council of abbottabad, J Ayub Med Coll Abbottabad 2010:22(3)

[2] Kanjilal et al. Nutritional status of children in India: household socio-economic condition as the contextual determinant, International Journal for Equity in Health 2010, 9:19

[3] The lancet, Nutrition: a quintessential sustainable development goal, http://dx.doi.org/10.1016/ S01406736(13)61100-9, June 6, 2013

[4] UNICEF, improving child nutrition the achievable imperative for global progress, 3 United Nations Plaza, New York, NY 10017 USA, April 2013

[5] Government of the Federal Democratic Republic of Ethiopia, national nutrition programme, June 2013-June 2015

[6] Olivier Ecker, Clemens Breisinger the food security system, IFPRI, March 2012

[7] Sarah Coll-Black et al, targeting food security interventions when "everyone is poor": The case of ethiopia's productive safety net programme, IFPRI, ESSP II Working Paper 24 May 2011

[8] Regional Hunger \& Vulnerability Programme (RHVP), Lessons from Ethiopia on a scaled-up national safety net programme, wahenga brief number 14 august 2007

[9] Alive \& Thrive, infant and young child nutrition in ethiopia: a journalist's guide, February 2011

[10] Teshome et al, Magnitude and determinants of stunting in children underfive years of age in food surplus region of Ethiopia: The case of West Gojam Zone, Ethiop. J. Health Dev. 2009;23(2)

[11] Aweke KA et al, Nutritional status of children in food insecure households in two districts of north showa zone, Ethiopia, African Scholarly Science Communication Trust. 2012(12):2

[12] Mahama Saaka and Shaibu Mohammed Osman, Does Household Food Insecurity Affect the Nutritional Status of Preschool Children Aged 6-36 Months? Hindawi Publishing Corporation International Journal of Population Research; Volume 2013, Article ID 304169, 12 pages http://dx.doi.org/10.1155/2013/304169
[13] David W. Hosmer and Stanley Lemeshow. Applied logistic regression. Canada: Jhon Wiley \& Sons, Inc. 2000, 2nd edition.

[14] Mulugeta et al, Factors Contributing to Child Malnutrition in Tigray, Northern Ethiopia, East African Medical Journal. 2010 (87): 6

[15] Bwalya Bupe Bwalya, Influence of maternal characteristics on under-five nutritional status in Zambia, the University of Zambia Lusaka, 2013

[16] Senbanjo IO et al, Influence of socio-economic factors on nutritional status of children in a rural community of osun state, Nigeria

[17] Timothy T. Awoyemi et al.: Environmental and Socioeconomic Correlates of Child Malnutrition in Iseyin Area of Oyo State, Nigeria, Food and Public Health 2012, 2(4): 92-98

[18] Rabia Fentaw et al, Nutrition Research and Practice (Nutr Res Pract) 2013;7(2):122-131

[19] Nebiyu Melaku, Agro ecological comparison of levels and correlates of nutritional status of under five children in Dara District of Sidama zone, SNNPRS, Ethiopia, 2007

[20] E. BLOSS ET AL. Prevalence and Predictors of Underweight, Stunting, and Wasting among Children Aged 5 and Under in Western Kenya, Journal of Tropical Pediatrics, Vol. 50, No. 5, 2004

[21] Daniel Ayalew, determinants of the nutrition and health status of children in rural ethiopia: a longitudinal analysis, Addis Ababa University Electronic Library Thesis and Dissertation, July 2006

[22] Central Statistical Agency Addis Ababa, Ethiopia, ICF International Calverton, Maryland, USA, EDHS 2011

[23] Solomon Demissie, Amare Worku. Magnitude and Factors Associated with Malnutrition in Children 6-59 Months of Age in Pastoral Community of Dollo Ado District, Somali Region, Ethiopia. Science Journal of Public Health, 2013 (1): 4

[24] Salah E.O. Mahgoub et al, factors affecting prevalence of malnutrition among children under three years of age in Botswana, Africa journal of food agriculture nutrition and development, 2006(6):1

[25] Dinesh Kumar et al, Influence of Infant-feeding Practices on Nutritional Status of Under-five Children, Indian Journal of Pediatrics, Volume 73-May, 2006

[26] Ajao KO et al, Influence of Family Size, Household Food Security Status, and Child Care Practices on the Nutritional Status of Under-five Children in Ile-Ife, Nigeria, African Journal of Reproductive Health December 2010; 14(4): 123

[27] The Use of Whole Cow's Milk in Infancy, Pediatrics 1992; 89; 1105, http://pediatrics.aappublications.org/content/89/6/1105

[28] Nebiyu Melaku, Agro ecological comparison of levels and correlates of nutritional status of under five children in Dara District of Sidama zone, SNNPRS, Ethiopia, 2007 